\title{
Psychological distress after the Great East Japan Earthquake: two multilevel 6-year prospective analyses CORRIGENDUM
}

Robin Goodwin, Kemmyo Sugiyama, Shaojing Sun, Jun Aida and Menachem Ben-Ezra

https://doi.org/10.1192/bjp.2019.251, Published online by Cambridge University Press, 2 December 2019

Keywords: Disasters; multilevel analyses; psychological distress; Japan

An error was made in the original paper. Prevalence of MMI and SMI for the complete sample should be as follows: $20.9 \%$ of respondents reported indications of moderate mental illness in wave 1 (2011; $\mathrm{n}=969)$, declining to $14.2 \%$ at wave $6(2016 ; \mathrm{n}=2263)$; $10.2 \%$ reported risk of severe mental illness in 2011, 5.6\% in 2016. The erroneous frequencies reported were not used in the modelling.
Robin Goodwin Kemmyo Sugiyama; Shaojing Sun; Jun Aida; Menachem BenEzra

\section{Reference}

Goodwin R, Sugiyama K, Sun S, Aida J and Ben-Ezra M. Psychological distress after the Great East Japan Earthquake: two multilevel 6-year prospective analyses. Br J Psychiatry 2020; 216: 144-150. 